\title{
The Mental Health Effects of Torture Trauma and Its Severity: A Replication and Extension
}

\author{
Ibrahim A. Kira ${ }^{1 \#}$, Jeffery S. Ashby ${ }^{2}$, Lydia Odenat ${ }^{3}$, Linda Lewandowsky ${ }^{4}$ \\ ${ }^{1}$ Center for Cumulative Trauma Studies, Stone Mountain, USA \\ ${ }^{2}$ Georgia State University, Atlanta, USA \\ ${ }^{3}$ Emory University, Atlanta, USA \\ ${ }^{4}$ University of Massachusetts, Amherst, USA \\ Email: "kiraaref@aol.com
}

Received February $23^{\text {rd }}, 2013$; revised March $25^{\text {th }}, 2013$; accepted April $22^{\text {nd }}, 2013$

Copyright (C) 2013 Ibrahim A. Kira et al. This is an open access article distributed under the Creative Commons Attribution License, which permits unrestricted use, distribution, and reproduction in any medium, provided the original work is properly cited.

\begin{abstract}
To clarify the effects of torture trauma and its components on PTSD and other mental health conditions, we investigated the relationship between measures for PTSD, Cumulative trauma disorders CTD, cumulative life trauma, torture and torture severity in a sample of 326 torture survivors. Hierarchical multiple regressions found no significant association between torture and PTSD. However, when we examined the effects of different types of torture we found witnessing and sexual tortures were significant predictors of PTSD and CTD. Path analysis results found that torture trauma and its severity may not be predicative of PTSD; but it is highly predictive of the more complex syndromes of CTD. The implications of the results for treating torture survivors were discussed. One of the important findings is the potential effects of torture on decreased re-experiencing and emotional numbness. Torture trauma may be too emotionally and physically painful experience that tends to be suppressed decreasing re-experiencing and increasing dissociation.
\end{abstract}

Keywords: Torture Trauma; Cumulative Trauma Disorders; PTSD; Cumulative Trauma

\section{Introduction}

Torture is a complex multilateral trauma as it consists of different trauma types that are focused on humiliating or annihilating the person's personal and collective identities (for a review of torture definitions, see, Quiroga, \& Jaranson, 2005). It is the intentional infliction of psychological, physical, and/or emotional pain or deprivation. It is a practice commonly used in substantial array of societies for purposes of punishment, intimidation, interrogation, and coercion (Pope, 2001). Torture is directed towards instilling and reinforcing a sense of powerlessness and terror in victims and their perspective communities, and/or political or religious groups. In this way, torture may be characterized as inter-group victimization with negative effects that go beyond individuals to families and communities.

The negative effects of torture on health, especially on neurological systems, for example, closed head and physical injuries, are well documented (e.g., Kira et al., 2006, Vorbrüggen \& Baer, 2007). However, the negative mental health effects of torture and its dynamics are not completely understood, which confuse clinicians who want to design appropriate interventions to this type of traumas. A meta-analysis of 181 surveys on tortured populations from 40 countries found that rates of PTSD and depression showed large variability ( $0 \%$ - 99\% for PTSD and 3\% - 85.5\%, for depression) (Steel, Chey, et al., 2009). An-

\footnotetext{
*Disclosure and acknowledgements: All authors report no competing interests.

${ }^{\#}$ Corresponding author.
}

other meta-analysis (Johnson \& Thompson, 2008) concluded that most epidemiologically-sound studies found relatively low rates of PTSD following torture. However, Steel and colleagues' (2009) meta-analysis found that reported torture emerged as the strongest factor associated with PTSD, followed by cumulative exposure to potentially traumatic events (PTE). However, most studies of the effects of torture have not controlled for the potentially confounding effects of other life traumas that happened before and after the torture. There is good evidence supporting a dose-response relationship between cumulative trauma and development and maintenance of PTSD in torture survivors (e.g., Johnson \& Thompson, 2008; Mollica, McInnes, Poole, \& Tor, 1998). In two large community studies of Iraqi refugees, torture did not predict the elevation of symptoms of PTSD, after controlling for the effects of traumas occurring before and after torture, (Kira et al., 2006). Recent study by Hollifield, Warner, \& Westermeyer, 2011, replicated these results.

Hooberman, Rosenfeld, et al. (2007), found that witnessing torture of others or of family members, and deprivation or passive torture were not associated with PTSD, anxiety, or depresssion symptoms, and the only factor associated with these symptoms was the torture rape. However, Basoglu (2009) found that while physical torture did not predict PTSD, psychological torture did. Similar results of Basoglu's were found in a study of tortured ex-prisoners who presented with elevated risk of poor health outcomes after exposure to psychological torture (Punamaki, Qouta, \& Sarraj, 2010). Rasmussen, Rosen- 
feld, Reeves, \& Keller (2007) found that chronic injuries resulting from torture mediated the path between torture and PTSD. They also found that injuries, but not torture, were associated with major depression, and that injuries did not moderate the relationship between major depression and torture.

Other variables, such as gender, ethnicity, and age, have also been identified as significant risk factors in the development of PTSD and may overlap with torture's effects among refugee populations. Gender discrimination, defined as the assignment of values to real or imagined differences between genders, has been found to be associated with PTSD and cumulative trauma related disorders (CTD) (complex PTSD)in female torture survivors (Kira, Smith, Lewandowski, \& Templin, 2010). With regard to age, torture survivors from Kosovo who were over the age of 65 were found to be at increased risk of PTSD as compared to their younger counterparts (Johnson \& Thompson, 2008). Finally, the experience of discrimination among refugee torture survivors has been associated with PTSD and CTD (e.g., Kira, Lewandowski, et al., 2010),

The goal of the current study was to clarify the relationship of torture trauma and its severity to PTSD and cumulative trauma related disorders (CTD). In addition, this study was designed to further explore which components of torture are related to different negative mental health outcomes after controlling for all other traumas that occurred before and after the torture. The objective is to further our understanding of the dynamics of torture to help identify the effective interventions. While the focus of the study is on the effects of torture, the interventions that may be effective, giving the outcome of the study will be discussed, in detail in its last part.

\section{Methods}

\section{Hypotheses}

Hypothesis 1) Torture trauma will not predict PTSD symptom clusters but will predict the more severe CTD syndromes after controlling for the effects of all other life time traumas.

Hypothesis 2) Some extreme torture components, i.e., anal rape, suffered gunshot and/or electric shock during torture, will be more associated with PTSD and CTD symptoms.

\section{Procedures}

The study was conducted on an existing clinical database developed by a center in US that provides wraparound services exclusively to torture survivors and gathers mental health data from all its clients. The instruments used for data collection were designed by the center psychologists. The instruments included a comprehensive intake that comprises detailed torture assessment, in addition to mental health screening that included measures for PTSD, cumulative trauma related disorders (CTD), and a cumulative life trauma measure that assesses the occurrence of different trauma types, including gender discrimination. Additionally, a comprehensive assessment of torture experience was part of intake. The data collection was conducted through face to face interviews by the center qualified professional and paraprofessional bi-lingual staff, usually in two sessions. The procedures in the clinic met all HIPPA regulations concerning clients' protection and include consent for use of the collected data in anonymous research. The study was approved by Georgia State University Institutional Review Board.

\section{Participants}

The study utilized a data base of a center that served refugee torture survivors in the Midwest region of USA contained 395 clients that include adults and adolescents. We excluded adolescents as they were relatively small number. Clients included in the study were 326 that comprise 200 primary and $126 \mathrm{sec}-$ ondary torture survivors (primary torture survivor is the person that had been subjected directly to torture, while secondary torture survivor is one of his/her family members, i.e., spouse, children, and/or parents). All participants were refugees who have legal status in US. Most of them have been referred to the program, in the first three months upon arrival for being suffered of torture in their own country and need assessment for service needs. Being tortured abroad for political reasons was the only eligibility criteria for admission. Participants were admitted between April 2008 and September 2009. They were not necessarily mental health clients; however, about $40 \%$ were referred to mental health services either for intervention or prevention. They came from 30 countries with the top four source countries being Burma $(n=86)$, Iraq $(n=85)$, Bhutan $(n=73)$, and Somalia $(\mathrm{n}=27)$. Participants include 37 from other 13 African countries (Zimbabwe, Uganda, Togo, Sudan (Darfuri), Rwanda, Nigeria, Liberia, Ivory Coast, Ethiopia, Eritrea, Congo, Chad, \& Burundi). The rest (18 participants) came from different countries in Asia, South America, and Europe (e.g., Afghanistan, Vietnam, Russia, Iran, Cuba, Colombia, and China). Participants included 185 (56.7\%) males and 141 (43.3\%) females. While gender representation in some sub-groups was almost balanced (Iraqi 52\% males, 48\% females, Bhutanese $45.6 \%$ males and $54.4 \%$ females), it was lopsided either way in the other sub-groups (Burmese: 67.7\% males, 32.3\% females, Somali: $32.3 \%$ males and $67.7 \%$ females; other African countries: $64.9 \%$ males and $35.1 \%$ females; other non-African countries: $72.2 \%$ males and $27.8 \%$ females). Age ranged from 18 to $76($ mean $=38.55, \mathrm{SD}=11.59)$.

Twenty percent of the clients was identified as illiterate, $24.4 \%$ completed primary school, $34.9 \%$ high or secondary school, $16.3 \%$ technical/vocational school, $1.2 \%$ had college degrees and $3.2 \%$ had post graduate degrees. With regard to marital status, $64.5 \%$ of them were married and living together with their spouse, $16.0 \%$ were single (never married), $2.3 \%$ divorced, $8.3 \%$ widowed, $1.6 \%$ identified their spouse as missing, $5.7 \%$ had spouses living in native country, $0.7 \%$ were separated by choice, and $0.9 \%$ were living with a partner.

\section{Construction and Translation of Measures in the Data Base}

The intake protocol and other measures utilized in the center were first constructed in English and subsequently translated into refugee major languages (Arabic, Bhutanese, and Burmese) by bilingual professionals. Measures were then back-translated by another fluent professional and reviewed for accuracy. After confirmation of the accuracy of the translations, the measures were pilot tested in focus groups. Previous studies have supported the psychometrics of the translated instruments with Iraqi refugees (Kira et al., 2006, 2008). For clients who speak only dialects or other languages, an interpreter translated the questionnaire directly to them.

\section{Measures}

PTSD Measure - Clinician-Administered Posttraumatic Stress 
Scale (CAPS-2) (18 items) (Blake et al., 1990) is widely used to assess PTSD. It is a structured clinical interview that assesses 17 PTSD symptoms rated on frequency and severity on a 5 -point scale. It has demonstrated high reliability with a range from $0.92-0.99$ and showed good convergent and discriminant validity. The center used its frequency sub-scale that is currently widely used in psychiatric literature. It has, in this mixed sample, Cronbach alpha reliability coefficient of 0.94 for all participants, which indicates a good reliability. The scale has four sub-scales: re-experiencing, avoidance, arousal and emotional numbness/dissociation. Reliability of the four sub-scales in our sample are adequate to high (alphas are 0.96, 0.92, 0.89 and 0.85 respectively). Further the alpha coefficients were high across all national origin groups (Bhutanese $=0.92$, Burmese $=$ 91, Iraqi $=0.85$, Somali $=0.96$, others $=0.97$.

Cumulative Trauma related Disorders Measure CTD (15 items) (Kira et al., 2012a). The CTD was developed on five community and clinic samples of adult and adolescent Iraqi refugees, Arab Americans, and African Americans. It is designed to assess 13 different symptoms: depression, anxiety, somatization, dissociation, auditory and visual hallucinations, avoidance of being with people, paranoid ideations, concentration and memory deficits, loss of self-control, feeling too harsh with family and with people in general, feeling suicidal, and feeling like hurting self. Exploratory and confirmatory factor analyses offered support for four factors: Executive function deficits, suicidality, psychosis/dissociation, and depression/anxiety interface. The CTD scale has shown good internal consistency reliability (alphas ranging from 0.85 to 0.98 ). Test-retest reliability in a 6 week-interval was 0.76 . Several studies also offer support for the CTD predictive validity. In the current diverse sample the Cronbach alpha reliability coefficient for the overall scale was 0.98 . Reliability of the four sub-scales was found to be high $(0.95,0.97,0.98$, and 0.96 respectively). Coefficients alpha were high across all groups (Bhutanese $=0.93$, Burmese $=94$, Iraqi $=0.94$, Somali $=0.89$, others $=0.94$.

CTS Cumulative Trauma Scale (32 items) short form: The CTS is designed to screen for the occurrence and frequency of traumas and stress across one's life time. The measure was developed based on development-based taxonomy of traumatic stressors. A number of studies with Iraqi refugees have offered support for the scale's reliability, and construct, divergent, convergent, and predicative validity (Kira et al., 2008, Kira et al., 2011, Kira, Fawzi, \& fawzi, 2012). The measure included six main subscales (attachment, personal identity, collective identity, and family, secondary, and survival traumas). Different sub-categories were further added, e.g., gender discrimination, and torture. The total score represents the cumulative trauma load that the individual has endured across the life span. The measure has, in this mixed sample an adequate alpha reliability coefficient of 0.81 . Alpha reliabilities for the sub-scales in the present data are as follows: Torture $=0.89$ ( 2 items scale), gender discrimination, GD $(2$ items scale $)=0.68$, survival trauma $(3$ items scale $)=0.69$, secondary traumas $(3$ items scale $)=0.66$, personal identity traumas $(15$ items scale $)=0.72$ and collective identity traumas $(6$ items scale $)=0.68$. Some reliability coefficients of the sub-scales can be relatively questionable but are usually acceptable for short sub-scales with binary response questions (e.g., Schmitt, 1996).

Further the alpha coefficients for CTS (the total scale) were adequate across all national origin groups (Bhutanese $=0.86$, Iraqi $=0.80$, Somali $=0.70$, others $=0.80$ ).
Torture severity scale: The measure developed in this study is based on the questions in the intake that include detailed information about torture experience and story. It comprises 61 stressors for the torture experience that include the duration of the torture event and the different exposure to physical torture, psychological or indirect torture, sexual torture, and prison conditions, with 0 assigned for each torture event that has not been experienced and 1 for each torture event that has been experienced. The total number of all torture stressors experienced in the first torture episode was used as a measure of "objective" torture severity. The higher score indicated higher exposure to torture events and vice versa. The measure has a Chronbach of alpha of (0.87).

Principal component factor analysis of all torture stressors, (factor extraction was based on Eigen value greater than 1.00 and scree plot with varimax rotation) yielded eight factors that accounted for $54.26 \%$ of the variance and included: general factor, witnessing, environment restriction, physical and formal accusations, sexual torture, for example beating on genitals, physical torture, extreme exposure to heat or cold, and sexual rape. On previous factor analysis study on torture component, Hooberman, Rosenfeld et al., 2007, found similar structure. Accordingly, seven torture severity sub-scales were constructed and the last eighth factor was dropped as its coefficient alpha was too low. The followings are the constructed sub-scales:

1) Torture General Factor sub-scale included 21 items that comprised different torture stressors that compose most of the different torture types. Coefficient alpha of this factor was 0.95

2) Witnessing (psychological torture) sub-scale included 7 items that focused mostly on seeing or hearing torture, seeing rape, dead bodies, seeing killing, witnessing torture of family members. Coefficient alpha of this factor was 0.84 .

3) Deprivation (passive torture) sub-scale Included 4 items that focused on climate control, no windows, no bed. Coefficient alpha of this factor is 0.88 .

4) Aggressive accusations and Legal procedures sub-scale Included 10 items and focused on forced accusations and pressures to confess through several means, Coefficient alpha of this factor was 0.74 .

5) Sexual torture sub-scale Included 3 items that focused on sexual torture, e.g., beating on genital and forced nudity. Coefficient alpha of this factor was 0.99 .

6) Physical torture sub-scale included 6 items and focused on physical torture, e.g., burnt, electrocuted, suspended, forced experiments. Coefficient alpha of this factor was 0.70 .

7) Aggressive environmental control included five items and focused on exposure to extreme heat or cold, and exposure to light Coefficient alpha of this factor was 0.64.

Additionally we used five single items: Anal rape, vaginal rape, suffered gunshot, electric shock, solitary confinement, and exposure to extreme cold, as single item measures for specific extreme torture experiences that stand alone.

\section{Data Analysis}

Analyses included partial correlation between torture variables and PTSD, and CTD and their symptom clusters. ANOVA explored the differences between the cultural and national origin groups, in PTSD, CTD, torture severity, trauma types, and cumulative trauma using Bonferroni post hoc test. Hierarchical multiple regressions explored the relationships of PTSD and $\mathrm{CTD}$ and their sub-scales as dependent variables, and torture 
sub-scales, and other trauma types and demographics as independent variables to determine which the significant predictors are. Path analyses tested different plausible path models for the effects of torture and torture severity as well as all other trauma types, using AMOS 19 software, (Arbuckle, 2006). Bootstrap with bias-corrected confidence intervals tested the significance of the direct and indirect effects and confidence interval of each variable. Bootstrapping is often used to get a better approximation of sampling distribution of a statistic than its theoretical distribution provides, when assumption of normality is violated.

\section{Results}

\section{Participants' Torture Experiences}

For primary torture survivors $(n=200)$, over $90 \%$ reported that they had been severely beaten, over $84 \%$ had been threatened or received a death threat, and over $69 \%$ indicated their relatives had been threatened. Over $11 \%$ of them reported having been stabbed, over $32 \%$ had suffered crushing injury, and one had his leg amputated. Over 13\% reported having been burnt, over $26 \%$ having been suspended upside down, $8 \%$ had suffered gunshot, and over $12 \%$ had been electrocuted. Over $58 \%$ of them reported that they had been shackled, over $4 \%$ suffered forced experiments, over $7 \%$ had their body parts stretched, over $13 \%$ had been exposed to extreme heat, or to extreme cold or both, and over $20 \%$ forced to walk on their knees. Over $34 \%$ reported that they had been subjected to forced labor. Over $47 \%$ reported that they had seen dead bodies, and over $73 \%$ had to witness others severely tortured. Over $16 \%$ had been in solitary confinement. Over $30 \%$ reported to witnessing killing, and over 3\% reported witnessing mock executions. Over $25 \%$ reported that they forced to confess, over $10 \%$ forced to accuse others, over $35 \%$ had been falsely accused, and over $22 \%$ forced to sign papers. Over $6.5 \%$ reported that they had been raped either vaginally or anally or both, and over $55 \%$ had been suspended by testicles, or had penis intrusion or both. Over $21 \%$ reported that they witnessed rape. Over $65 \%$ reported inappropriate toilet, bath, food, sleep, medical care, and overcrowded cells.

\section{Differences between National Groups in Trauma Load, Types, and Profiles}

The mean number of trauma types occurrence (cumulative trauma) endured for all sample participants was 10.89 with SD of 4.18, with the highest trauma load was among the African group (mean of 12.85, with SD of 5.79 ) and the least was among the Burmese group (mean of 9.149, with SD of 2.85). The differences between African group and Burmese, Bhutanese and Iraqi and between Somali and Burmese groups were significant. For trauma types while there was no significant differences between group in attachment trauma with low occurrence for all, as family and cultural values minimize parents abandonment of their children. There were, also, no significant differences between these generally patriarchic cultures in the level of gender discrimination. Additionally, there were no differences between the groups in collective identity trauma (e.g., discrimination and oppression), which is the highest occurrence compared to other trauma types and seem to be the core trauma for all groups along with torture. For personal identity, survival, and secondary traumas, Somali, Iraqi and African groups had significantly higher loads in these trauma types than
Burmese and Bhutanese groups. For role identity trauma, Iraqi group scored the highest among all the other groups and the differences between them and all other groups were significant. This may be related to the relatively higher level of education which made them less employable for jobs equal to their qualification in the US.

Concerning torture severity the Somali group scored the highest in torture severity (mean of 15.42, with SD of 11.96), while the Burmese group scored the lowest (mean of 8.58 , with SD of 9.52). The differences between Somali and Burmese groups were statistically significant; otherwise there were no significant differences between the other groups in torture severity. The between group differences in all variables, except for torture severity, attachment trauma, gender discrimination and collective identity, were significant.

\section{Partial Correlation Results}

Partial correlation between torture trauma and other trauma types (controlling for age, marital status, education and gender) indicated that torture trauma was highly associated with survival trauma $\left(0.39^{* * *}\right)$, personal identity trauma $\left(0.38^{* * *}\right)$, and secondary traumas $\left(0.20^{* * *}\right)$. It was negatively associated with role identity or achievement traumas $\left(-0.18^{* * *}\right)$, which may indicate that torture survivors are mostly achievers. Partial correlation between torture trauma, torture severity and its seven factor analysis based sub-scales and PTSD, CTD and their sub-scales indicated that while torture trauma was not associated with PTSD or CTD, it was significantly associated with PTSD arousal and CTD Psychoticism/dissociation sub-scales. Witnessing torture sub-scale was associated with PTSD and CTD. It was associated with all PTSD four sub-scales. Sexual torture sub-scale was associated with CTD (but not with PTSD), It was associated with depression/anxiety comorbidity, suicidality, and emotional numbness/dissociation sub-scales. Anal rape with associated with psychoticism/dissociation, and emotional numbness/dissociation sub-scales. Vaginal rape was associated with executive functions deficits. Suffered from gunshot during torture was significantly associated with CTD Psychosis/dissociation sub-scale and PTSD arousal and emotional numbness/dissociation sub-scales. Electrocution and solitary confinement were associated with PTSD emotional numbness/ dissociation sub-scale. Exposure to extreme cold was negatively associated with CTD and CTD depression/anxiety comorbidity, executive function deficits sub-scale, and with PTSD re-experiencing and avoidance sub-scales. The results concerning exposure to extreme cold warrant further discussion. Table 1 details these results.

\section{Hierarchical Multiple Regression Analyses Results}

For all regression analyses that we conducted, we tested for multi-colinearity. VIF (variance inflation factor) for all predictor variables ranged between 1.00 and 1.40 , which indicated low colinearity (the recommended cut off score for multicolinearity is 5.00, e.g., O'Brien, 2007). In the first round of hierarchical multiple regression analyses, we tested the effects of torture and torture severity on PTSD and CTD. To control for age, gender, education, marital status and cumulative trauma excluding torture trauma, with PTSD and CTD as dependent variables and age, gender, education and marital status as independent variables in the first step, and added torture 
Table 1.

Partial correlations between torture, torture severity factors and mental health variables.

\begin{tabular}{ccccccccccc}
\hline & CTD & PTSD & CTD-D & CTD-E & CTD-P & CTD-S & PTSD-R & PTSD-AV & PTSD-AR & PTSD-N \\
\hline Torture scale & 0.07 & $0.10^{+}$ & 0.025 & $0.10^{+}$ & $0.15^{*}$ & 0.05 & 0.03 & 0.08 & $0.17^{* *}$ & $0.10^{+}$ \\
Torture severity scale & 0.05 & 0.08 & 0.07 & $0.11^{+}$ & 0.08 & -0.001 & 0.06 & 0.09 & 0.07 & 0.07 \\
$\begin{array}{c}\text { General factor of torture } \\
\text { Witnessing }\end{array}$ & 0.01 & 0.07 & 0.03 & 0.08 & 0.03 & -0.003 & 0.05 & 0.09 & 0.06 & 0.05 \\
$\begin{array}{c}\text { (psychological torture) } \\
\text { Deprivation }\end{array}$ & $0.13^{*}$ & $0.15^{*}$ & $0.11^{+}$ & $0.10^{+}$ & 0.09 & 0.09 & $0.12^{*}$ & $0.13^{*}$ & $0.13^{*}$ & $0.14^{*}$ \\
$\begin{array}{c}\text { (passive torture) } \\
\text { Formal accusation and } \\
\text { procedures }\end{array}$ & 0.04 & -0.03 & -0.01 & 0.09 & -0.004 & 0.08 & -0.01 & -0.04 & -0.06 & 0.02 \\
$\quad \begin{array}{c}\text { Sexual torture } \\
\text { Physical torture }\end{array}$ & 0.01 & 0.02 & 0.04 & -0.01 & -0.02 & -0.05 & 0.01 & 0.05 & 0.02 & 0.01 \\
$\quad-0.003$ & 0.06 & 0.04 & -0.07 & 0.07 & 0.07 & 0.05 & 0.01 & 0.08 & 0.04 \\
Aggressive \\
environmental control
\end{tabular}

Note: $\mathrm{CTD}=$ Cumulative Trauma related Disorders, PTSD = Post-Traumatic Stress Disorders, CTD-D = CTD Depression and Anxiety comorbidity, CTD-E Executive Functions Deficits, CTD-P= Psychoticism/Dissociation; CTD-S = Suicidality; PTSD-R = Re-experiencing; PTSDAV = Avoidance; PTSD-A = Arousal; PTSD-N = Emotional Numbness/Dissociation ${ }^{*} p<0.05 .{ }^{* *} p<0.01 .{ }^{+} p<0.10$. Two-tailed.

trauma, torture severity, anal rape and vaginal rape in the second step and added Cumulative Trauma Excluding Torture in the Third step. In the final regression model, only cumulative trauma excluding torture, marital status and anal rape showed significant prediction of PTSD. Cumulative trauma excluding torture, and vaginal rape showed significant prediction of CTD. Table 2 describes these results.

\section{Path Analysis Results}

We checked the different plausible models for the association between torture trauma, torture severity, all other trauma types and PTSD and CTD and their sub-scales. The models we tested replicated or did not go far from regression results, but highlighted the severe effects of torture that go beyond simple PTSD. The first model we present has torture trauma, torture severity, and all other cumulative traumas as independent variables, and PTSD four factors as dependent variables. The model has good fit with the data (Chi Square $=3.690$, d.f. $=7, p$ $=0.815, \mathrm{CFI}=1.00$, RMSEA $=0.000)$. In the model, Cumulative traumas (other than torture) have highly significant direct effects on re-experiencing, direct and direct effects on arousal, and avoidance, and indirect effects on emotional numbness/dissociation. On the other hand, torture trauma has close to significant negative effects on all PTSD components. However, torture severity, have significant effects on increased arousal and numbness/dissociation. Figure 1 and Table 3 present the model.

The second model we present has torture trauma, torture severity, and all other cumulative traumas as independent variables, and CTD four syndromes as dependent variables. The model has good fit with the data (Chi Square $=9.474$, d.f. $=6, p$ $=0.149, \mathrm{CFI}=0.995$. RMSEA $=0.004)$. In the model all other life traumas have significant direct and indirect effects on depression/anxiety comorbidity, executive function deficits, and psychosis/dissociation syndromes, as well as indirect significant effects on suicidality. Torture trauma, on the other side has direct and indirect effects on executive function deficits, and significant indirect effects on depression/anxiety comorbidity, suicidality and psychosis/dissociation syndromes. Additionally, torture severity, has direct effect on executive function deficits, and indirect effects on depression/anxiety comorbidity syndromes. Torture seems to have more severe mental health effects than PTSD. Figure 2 and Table 4 present the model.

\section{Discussion}

The results of the study generally confirmed study hypotheses and replicated findings from some previous studies. They also offer some possible explanations that identify some of the dynamics of the effects of torture. Partial correlation and hierarchical regression results found that torture trauma and torture severity were not significant predictors of PTSD, other cumulative life traumas that happened before and after torture were the highly significant predictors. These results replicated previous findings of Kira et al., 2006; and Hollifield et al., 2011. Path analysis results indicated that torture predicted as hypothized the more severe symptoms of CTD (Complex PTSD).

For torture types, while physical torture did not predict PTSD or CTD, witnessing or psychological torture predicted CTD, and PTSD, replicating Basoglu et al.'s (2009) findings. 
Table 2.

Hierarchical Regression analyses with PTSD and CTD as Dependent Variable and Age, Gender, Education and Marital status as independent variables in the first step, and added torture Trauma, Torture Severity, Anal rape and Vaginal rape in the second step and added Cumulative Trauma Excluding Torture in the Third step.

\begin{tabular}{|c|c|c|c|c|c|c|c|c|}
\hline \multirow{2}{*}{$\begin{array}{c}\text { Dependent sariables } \\
\text { Predictors sntered }\end{array}$} & \multicolumn{4}{|c|}{$P T S D$} & \multicolumn{4}{|c|}{$C T D$} \\
\hline & $B$ & $S E(B)$ & $\beta$ & $R^{2}$ (Change) & $B$ & $S E(B)$ & $\beta$ & $R^{2}$ (Change) \\
\hline \multicolumn{9}{|l|}{ Fist step } \\
\hline Age & 0.19 & 0.08 & $0.13^{*}$ & $0.048^{*}$ & 0.14 & 0.05 & $0.15^{* *}$ & $0.039^{*}$ \\
\hline Gender & 1.67 & 1.89 & 0.05 & & 0.72 & 1.25 & 0.03 & \\
\hline Education & -0.28 & 0.79 & -0.02 & & 0.11 & 0.53 & 0.01 & \\
\hline Marital status & 1.35 & 0.49 & $0.15^{* *}$ & & 0.68 & 0.33 & $0.12^{*}$ & \\
\hline \multicolumn{9}{|l|}{ Second step } \\
\hline Age & 0.15 & 0.08 & $0.11^{+}$ & $\begin{array}{c}0.075 \\
\left(0.028^{+}\right)\end{array}$ & 0.118 & 0.054 & $0.13^{*}$ & $0.062(0.023)$ \\
\hline Gender & 3.07 & 2.21 & 0.09 & & 1.24 & 1.46 & 0.06 & \\
\hline Education & -0.18 & 0.80 & -0.01 & & 0.150 & 0.53 & 0.02 & \\
\hline Marital status & 1.23 & 0.49 & $0.14^{* *}$ & & 0.61 & 0.33 & 0.11 & \\
\hline Torture srauma & 1.84 & 1.21 & 0.10 & & 0.87 & 0.80 & 0.07 & \\
\hline Torture severity & 0.09 & 0.09 & 0.06 & & 0.07 & 0.06 & 0.07 & \\
\hline Anal rape & 18.13 & 9.38 & $0.11^{*}$ & & 9.17 & 6.23 & 0.08 & \\
\hline Vaginal rape & 6.16 & 5.43 & 0.06 & & 5.55 & 3.61 & 0.09 & \\
\hline \multicolumn{9}{|l|}{ Third step } \\
\hline Age & 0.10 & 0.07 & 0.07 & $0.274\left(0.198^{* * *}\right)$ & 0.083 & 0.049 & $0.09^{+}$ & $\begin{array}{l}0.254^{* * *} \\
(0.191)^{-1}\end{array}$ \\
\hline Gender & 2.98 & 1.96 & 0.09 & & 1.18 & 1.31 & 0.05 & \\
\hline Education & -0.14 & .71 & -0.01 & & 0.17 & 0.47 & 0.02 & \\
\hline Marital status & 0.86 & 0.44 & $0.10^{*}$ & & 0.36 & 0.30 & 0.06 & \\
\hline Torture srauma & -0.32 & 1.10 & -0.012 & & -0.53 & 0.74 & -0.04 & \\
\hline Torture severity & 0.04 & 0.08 & 0.03 & & 0.039 & 0.052 & 0.04 & \\
\hline Anal rape & 16.48 & 8.33 & $0.10^{*}$ & & 8.09 & 5.57 & 0.07 & \\
\hline Vaginal rape & 6.94 & 4.82 & 0.07 & & 6.05 & 3.22 & $0.10^{*}$ & \\
\hline $\begin{array}{c}\text { Cumulative trauma excluding } \\
\text { torture }\end{array}$ & 1.94 & 0.22 & $0.47^{* * *}$ & & 1.26 & 0.15 & $0.46^{* * *}$ & \\
\hline
\end{tabular}

Note: All regression models were significant $(p<0.000){ }^{*} p<0.05 .{ }^{* *} p<0.01 .{ }^{+} p<0.10$. Two-tailed.

Anal rape was associated with PTSD and CTD. Vaginal rape predicted CTD. These results replicated Hooberman et al., 2007, and Punamaki et al., 2010 findings on the development of PTSD symptom following sexual torture.

One of the important findings is the potential effects of torture on decreased re-experiencing and emotional numbness. Torture trauma is too emotionally and physically painful experience that tends to be suppressed decreasing re-experiencing and increasing dissociation. Recent longitudinal study found persistent dissociation among ex-prisoners of war (Zerach et al., 2013). That may explain the disappointing results of some previous studies that focused on torture effects on PTSD. This may explain why traditional exposure therapy is not recommended for torture survivor.

Another alternative explanation to this finding is the attribution of causes of torture, as a politically motivated inter-group violence. Fundamental attribution to external causes, for example, out-group or the enemy, who bears the responsibility for victimization and is less stable and less important than in-group, is less taxing than attribution to internal causes that denigrate selfesteem and self-efficacy and produce more stress and reexperiencing. Such fundamental attribution process may increase feelings of personal and collective self-esteem, instead, as he/she suffers for or to protect his/her group or/and its fundamental causes. The attribution process, in other personal identity trauma types, may have more internal locus of causation and self blame. Self-perceptions will strongly influence the ways in which people interpret their sufferings. Internalized vicarious group identity attributions buffer against decreased self-esteem associated with other traumas and gave them meaning to their suffering.

Another alternative or added explanation is the use of coping strategies and behaviors among torture survivors. Among study 


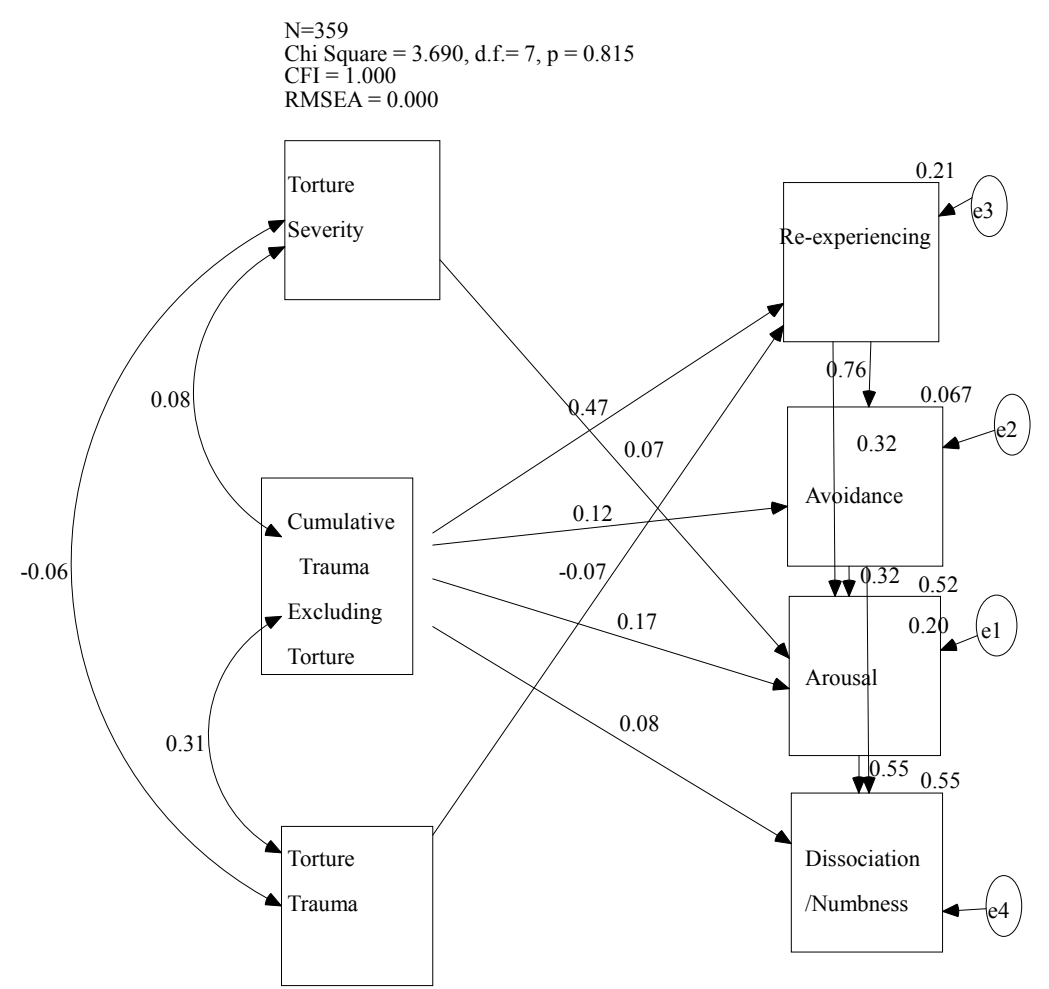

Figure 1.

Path Diagram for the Direct Effects of Torture, Torture severity and Other Life Traumas on PTSD Four Factors.

Table 3.

Decomposition of standardized direct, indirect, total effects and confidence intervals (95\%) of Torture, torture severity and other cumulative life traumas on PTSD Four Factors.

\begin{tabular}{|c|c|c|c|c|}
\hline \multirow[b]{2}{*}{ Causal variables } & \multicolumn{4}{|c|}{ Endogenous variables } \\
\hline & Re-experiencing & Avoidance & Arousal & $\begin{array}{c}\text { Emotional numbness/Mild } \\
\text { dissociation }\end{array}$ \\
\hline \multicolumn{5}{|c|}{ Torture trauma } \\
\hline Direct effects & $\begin{array}{c}-0.069 \\
(-0.162 / 0.029)\end{array}$ & 0.000 & 0.000 & 0.000 \\
\hline Indirect effects & 0.000 & $\begin{array}{c}-0.052 \\
(-0.120 / 0.020)\end{array}$ & $\begin{array}{c}-0.039 \\
(-0.089 / 0.017)\end{array}$ & $\begin{array}{c}-0.032 \\
(-0.076 / 0.013)\end{array}$ \\
\hline Total effects & $\begin{array}{c}-0.069 \\
(-0.162 / 0.029)\end{array}$ & $\begin{array}{c}-0.052 \\
(-0.120 / 0.020)\end{array}$ & $\begin{array}{c}-0.039 \\
(-0.089 / 0.017)\end{array}$ & $\begin{array}{c}-0.032 \\
(-0.076 / 0.013)\end{array}$ \\
\hline \multicolumn{5}{|c|}{ Cumulative trauma excluding torture trauma } \\
\hline Direct effects & $\begin{array}{c}0.472^{* *} \\
(0.396 / 0.537)\end{array}$ & $\begin{array}{c}0.125^{* *} \\
(0.073 / 0.189)\end{array}$ & $\begin{array}{c}0.173^{* *} \\
(0.089 / 0.254)\end{array}$ & $\begin{array}{c}0.077 \\
(-0.023 / 0.146)\end{array}$ \\
\hline Indirect effects & 0.000 & $\begin{array}{c}0.357^{* *} \\
(0.299 / 0.414)\end{array}$ & $\begin{array}{c}0.307^{* * *} \\
(0.262 / 0.374)\end{array}$ & $\begin{array}{c}0.359^{* *} \\
(0.279 / 0.436)\end{array}$ \\
\hline Total effects & $\begin{array}{c}0.472^{* *} \\
(0.396 / 0.537)\end{array}$ & $\begin{array}{c}0.482^{* *} \\
(0.406 / 0.552)\end{array}$ & $\begin{array}{c}0.480^{* * *} \\
(0.391 / 0.556)\end{array}$ & $\begin{array}{c}0.436^{* *} \\
(0.359 / 0.514)\end{array}$ \\
\hline \multicolumn{5}{|c|}{ Torture Severity } \\
\hline Direct effects & 0.000 & 0.000 & $\begin{array}{c}0.071^{*} \\
(0.008 / 0.135)\end{array}$ & 0.000 \\
\hline Indirect effects & 0.000 & 0.000 & 0.000 & $\begin{array}{c}0.039^{*} \\
(0.004 / 0.073)\end{array}$ \\
\hline Total effects & 0.000 & 0.000 & $\begin{array}{c}0.071^{*} \\
(0.008 / 0.135)\end{array}$ & $\begin{array}{c}0.039^{*} \\
(0.004 / 0.073)\end{array}$ \\
\hline Squared R & 0.207 & 0.671 & 0.518 & 0.547 \\
\hline
\end{tabular}

Note: ${ }^{*} p<0.05 .{ }^{* *} p<0.01 .{ }^{+} p<0.10$. Two-tailed.

sample, $71 \%$ attributed their survival to religious beliefs, $53 \%$ to family support, $41 \%$ to fate, $32 \%$ to will to survive, $4 \%$ to party and community support, and $3 \%$ to forgiveness. Primary torture survivors, compared to secondary torture survivors, were significantly attributing will to survive and community and political party support as factors in their survival compared 


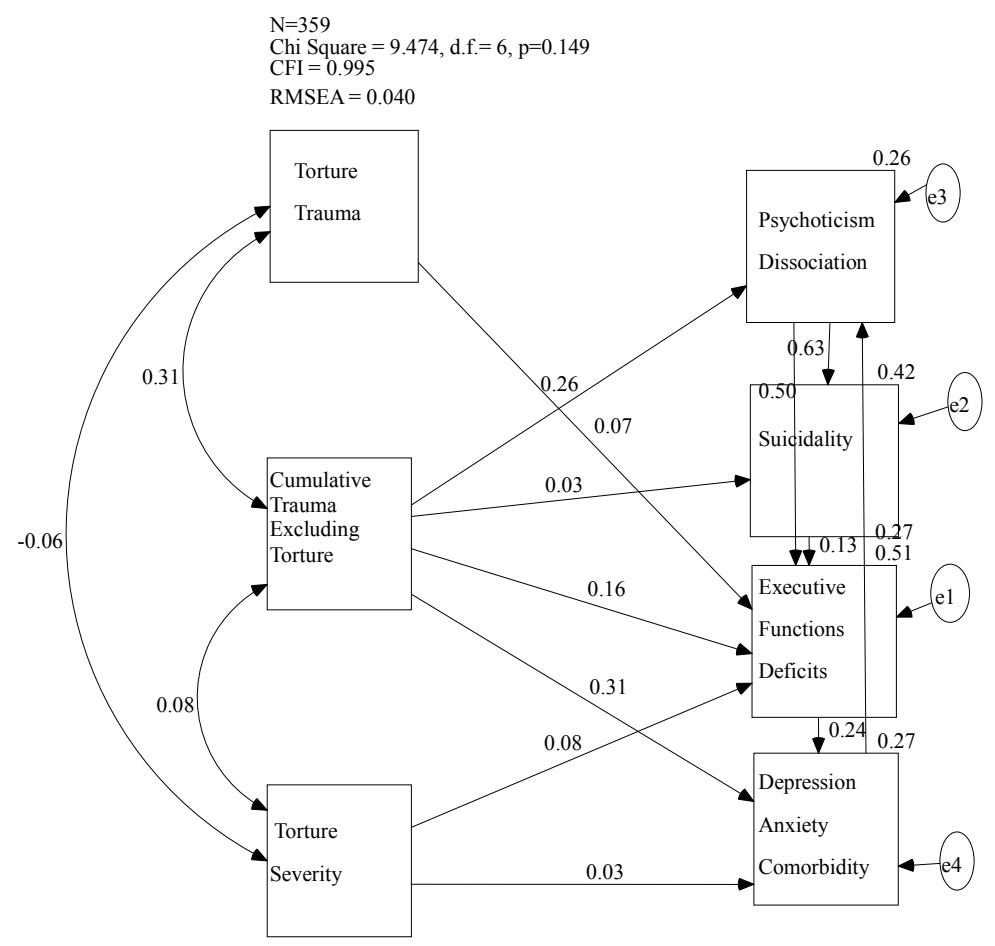

Figure 2.

Path diagram for the effects of torture, torture severity and other life traumas on PTSD four factors.

to secondary torture survivors. They express significantly less anger from God because what happened to them compared to secondary survivors. This may indicate more inner resiliency and post-traumatic growth. Previous study (Isakson, Jurkovic, 2013) concluded that reliance on belief and value systems, safety measures, and social support, despite continuing psychological and physical symptomatology, enabled the moving-on process for torture survivors.

The results of path analysis highlighted another potential or added explanation. While torture may be negatively associated with some of PTSD symptoms, it is associated with the more severe symptoms of dissociation, psychosis, and executive function deficits. Path analysis results showed small size significant effects of torture on depression/anxiety comorbidity and executive function deficits, and small indirect, but significant effects on dissociation/psychosis $\left(0.005^{*}\right)$, and suicidality $\left(0.003^{*}\right)$. Torture severity showed medium size direct effects on executive function deficits and depression/anxiety comorbidity.

Implications for torture treatments

By mapping the full blueprint of the torture effects, we hope the information will eventually lead to the development of more targeted interventions. One of the important findings of current study is that the highest and core trauma for all the cultural groups in current study was collective identity trauma (intergroup traumas). The political nature of torture as part of inter-group violence, contrasted by interpersonal violence should help develop targeted interventions more appropriate to this core trauma type. The potential effects of torture on decreased re-experiencing may help explain why clinicians report that traditional exposure therapy may be contraindicated with torture survivors and victims of severe trauma in general (e.g., Gleiser, Ford, \& Fosha, 2008; Kira, 2010). Intervention based on PTSD model and re-experiencing (e.g., traditional exposure therapy) may not be effective for some of them as their symptoms may be more severe. Force re-experiencing, can be re-traumatizing, worsening their condition, or force them to drop out.

Systematic review of treatment modalities for PTSD in refugee populations found that no treatment modality was firmly supported, but there was evidence for the effectiveness of narrative exposure therapy and cognitive-behavioral therapy (e.g., Crumlish, \& O'Rourke, 2010, Robjant, \& Fazel, 2010; Neuner et al., 2009). There is an empirical evidence of the effectiveness of trauma-focused CBT on refugees (e.g., Kruse, Joksimovic, Cavka, et al., 2010).

Working with complex traumas, such as torture, needs new framework for trauma recovery (e.g., Courtois, Ford, Herman, $\&$ van der Kolk, 2009). One of the other promising intervenetions, is the Trauma Adaptive Recovery Group Education and Therapy (TARGET; Courtois \& Ford, 2009; Ford \& Russo, 2006). TARGET views recovery from trauma as a shift from living in survival mode to focusing on personal growth and effectiveness in family, friendship, intimate, work, and community relationships. TARGET is a non-exposure therapy that uses skills building and experiential exercises in a group therapy format to address topics that include self-esteem, anger, grief, shame, guilt, relationships, revictimization, and spirituality.

An integrated model of recovery that combines individual and ecological approaches to recovery may be more indicated especially for those complex traumas that have political and inter-group components. It was suggested that adding cultural and the ecological considerations will reduce the limitations of the individual model of recovery and counter the confines of the medical model of services (e.g., Kira, 2010; Summerfield, 2004). Individual models of recovery (e.g., Herman, 1997) and 
Table 4.

Decomposition of standardized direct, indirect, total effects and confidence intervals (95\%) of torture, torture severity and other cumulative life traumas on CTD four factors.

\begin{tabular}{|c|c|c|c|c|}
\hline \multirow{2}{*}{ Causal variables } & \multicolumn{4}{|c|}{ Endogenous variables } \\
\hline & $\begin{array}{l}\text { Depression and anxiety } \\
\text { comorbidity syndrome }\end{array}$ & Executive function deficits & Suicidality & $\begin{array}{l}\text { Psychotic features and } \\
\text { dissociation }\end{array}$ \\
\hline \multicolumn{5}{|l|}{ Torture trauma } \\
\hline Direct effects & 0.000 & $\begin{array}{c}0.068^{*} \\
(0.027 / 0.138)\end{array}$ & 0.000 & 0.000 \\
\hline Indirect effects & $\begin{array}{c}0.017^{*} \\
(0.006 / 0.042)\end{array}$ & $\begin{array}{c}0.003^{*} \\
(0.001 / 0.007)\end{array}$ & $\begin{array}{c}0.003^{*} \\
(0.001 / 0.009)\end{array}$ & $\begin{array}{c}0.005^{*} \\
(0.002 / 0.012)\end{array}$ \\
\hline Total effects & $\begin{array}{c}0.017^{*} \\
(0.006 / 0.042)\end{array}$ & $\begin{array}{c}0.070^{*} \\
(0.027 / 0.143)\end{array}$ & $\begin{array}{c}0.003^{*} \\
(0.001 / 0.009)\end{array}$ & $\begin{array}{c}0.005^{*} \\
(0.002 / 0.012)\end{array}$ \\
\hline \multicolumn{5}{|c|}{ Torture Severity } \\
\hline Direct effects & $\begin{array}{c}0.032 \\
(-0.069 / 0.100)\end{array}$ & $\begin{array}{c}0.081^{*} \\
(0.005 / 0.154)\end{array}$ & 0.000 & 0.000 \\
\hline Indirect effects & $\begin{array}{c}0.021^{*} \\
(0.002 / 0.040)\end{array}$ & $\begin{array}{c}0.008 \\
(-0.005 / 0.022)\end{array}$ & $\begin{array}{c}0.009 \\
(-0.007 / 0.025)\end{array}$ & $\begin{array}{c}0.014 \\
(-0.010 / 0.037)\end{array}$ \\
\hline Total effects & $\begin{array}{c}0.053 \\
(-0.050 / 0.119)\end{array}$ & $\begin{array}{c}0.089^{*} \\
(0.008 / 0.165)\end{array}$ & $\begin{array}{c}0.009 \\
(-0.007 / 0.025)\end{array}$ & $\begin{array}{c}0.014 \\
(-0.010 / 0.037)\end{array}$ \\
\hline \multicolumn{5}{|c|}{ Cumulative Trauma (Excluding Torture) } \\
\hline Direct effects & $\begin{array}{c}0.314^{* *} \\
(0.242 / 0.408)\end{array}$ & $\begin{array}{c}0.158^{* *} \\
(0.065 / 0.233)\end{array}$ & $\begin{array}{c}0.027 \\
(-0.079 / 0.124)\end{array}$ & $\begin{array}{c}0.264^{* *} \\
(0.165 / 0.361)\end{array}$ \\
\hline Indirect effects & $\begin{array}{c}0.089^{* *} \\
(0.049 / 0.142)\end{array}$ & $\begin{array}{c}0.220^{* *} \\
(0.150 / 0.293)\end{array}$ & $\begin{array}{c}0.237^{* *} \\
(0.159 / 0.321)\end{array}$ & $\begin{array}{c}0.109^{* *} \\
(0.076 / 0.177)\end{array}$ \\
\hline Total effects & $\begin{array}{c}0.403^{* *} \\
(0.318 / 0.463)\end{array}$ & $\begin{array}{c}0.377^{* *} \\
(0.306 / 0.483) \\
\end{array}$ & $\begin{array}{c}0.264^{* *} \\
(0.131 / 0.393)\end{array}$ & $\begin{array}{c}0.374^{* *} \\
(0.277 / 0.478)\end{array}$ \\
\hline
\end{tabular}

Note: ${ }^{*} p<0.05,{ }^{* *} p<0.01,{ }^{+} p<0.10$. Two-tailed.

ecological models of recovery that have been suggested for interpersonal traumas (e.g., Harvey, 1996) needed to be adapted and adjusted to work with victims of torture and political violence (e.g., Miller, 1999). Holistic, interdisciplinary torture rehabilitation models emerged early on (by 1984) in Copenhagen by RCT group (e.g., Ortmann, Genefke, Jakobson, \& Lunde, 1987). Variants and expansions of the model have been emerged and further developed, for example, the wraparound approach for psycho-social rehabilitation of torture survivors (e.g., Silove, Tarn, Bowles, \& Reid, 1991; Kira, 2002, 2010), ecological group therapy models that focus on community healing (Kira, Ahmed et al., 2012b), post-disaster ecological recovery model, (Abramson et al., 2010). While such models have social and ecological validity as inherent programmatic feature, empirical evidence of its effectiveness is not yet established through controlled double blind studies. However, there is strong empirical evidence for the effectiveness of some of their variants (e.g., Abramson et al., 2010). There is some empirical evidence of the effectiveness of multi-component multi-systemic wraparound torture rehabilitation approach (e.g., McColl et al., 2010). There is need to develop or adopt such a multi-systemic, multi-component, multi-modal Therapies (MSMCT) that include individual, family, and community healing (c.f., e.g., Alexander, 2004, Kira, 2001, 2010 ). Community-based interventions that go beyond home-based family sessions have shown evidence of enhancing the generalizability and durability of treatment benefits (Kazdin \& Weisz, 1998).

Working with torture survivors, clinician should adopt mu- ltifocal conceptual lens that help widen the socio-political and cultural context that is usually missing in the therapeutic encounter with torture survivors. It is importance of having a working alliance that is characterized by a non-neutral attitude toward the core traumas of the patient. This highlights the "bond of commitment" required of therapists and the relevance of political affiliations and advocacy in these processes. This bond of commitment seeks to depathologize, demedicalize and normalize the survivor experiences and resulted symptoms (e.g., Becker, Lira et al., 1990).

\section{Limitations}

One limitation of the study was its cross-sectional nature, which only allowed investigators to draw probabilistic causality from the results. We realize the limitation of regression and path analyses with unobserved confounding variables that can distort statistical inference. It may be impossible to eliminate their effects in observational studies. However, in the cases where one cannot conduct experimental studies, regression and path analyses are powerful tools of analysis.

Further, several analyses were conducted which may increase the risk for type I errors. Caution should be exercised in interpreting the results that are not highly significant.

Another limitation of the study is that the measurement of cumulative trauma was based on participants' self-report which could be subject to bias of under or over-reporting of events due to current symptoms, embarrassment, shame, and social desirability. Despite these limitations, results provide associa- 
tions that help in the prediction and formulation of hypotheses for subsequent controlled designs, if possible. Plausible theoretical analysis and previous empirical studies suggest a probabilistic directionality of the effects.

\section{REFERENCES}

Arbuckle, J. L. (2006). Amos 7.0 user's guide. Chicago: SPSS

Abramson, D. M., Stehling-Ariza, T., Park, Y. S., Walsh, L., \& Culp, D. (2010). Measuring individual disaster recovery: A socioecological framework. Disaster Medicine and Public Health Preparedness, 4, 46-54. doi: $10.1001 / \mathrm{dmp} .2010 .14$

Alexander, J. C. (2004). Toward a theory of cultural trauma. In J. C. Alexander, R. Eyerman, B. Giesen, N. J. Smelser, \& P. Sztompka (Eds.), Cultural trauma and collective identity (pp. 1-30). Berkeley: University of California Press. doi:10.1525/california/9780520235946.003.0001

Başoglu, M. (2009). A multivariate contextual analysis of torture and cruel, inhuman, and degrading treatments: Implications for an evidence-based definition of torture. American Journal of Orthopsychiatry, 79, 135-145. doi:10.1037/a0015681

Becker, D., Lira, E., Castillo, M. I., Gómez, E., \& Kovalskys, J. (1990). Therapy with victims of political repression in Chile: The challenge of social reparation. Journal of Social Issues, 46, 133-149. doi:10.1111/j.1540-4560.1990.tb01939.x

Blake, D. D., Weathers, F. W., Nagy, L. M., Kaloupek, D. G., Klauminzer, G., Charney, D. S., \& Keane, T. M. (1990). A clinician rating scale for assessing current and lifetime PTSD: The CAPS-1. The Behavior Therapist, 13, 187-188.

Courtois, C., Ford, J., Herman, J., \& van der Kolk, B. (2009). Treating complex traumatic stress disorders: An evidence-based guide. Guilford: Guilford Press.

Crumlish, N., \& O'Rourke, K. (2010). A systematic review of treatments for post-traumatic stress disorder among refugees and asylumseekers. Journal of Nervous and Mental Disorders, 198, 237. doi:10.1097/NMD.0b013e3181d61258

Ford, J., \& Russo, E. (2006). Trauma-focused present-centered emotional self-regulation approach to integrated treatment for posttraumatic stress and addiction: Trauma adaptive recovery group education and therapy (TARGET). American Journal of Psychotherapy, 60, 335-355.

Gleiser, K., Ford, J., \& Fosha, D. (2008). Contrasting exposure and experiential therapies for complex PTSD. Psychotherapy: Theory, Research, Practice, Training, 45, 340-360. doi:10.1037/a0013323

Harvey, M. (1996). An ecological view of psychological trauma and trauma recovery. Journal of Traumatic Stress, 9, 3-23. doi: $10.1002 /$ jts. 2490090103

Herman, J. (1997). Trauma and recovery. New York: Basic Books.

Hollifield, M., Warner, T., \& Westermeyer, J. (2011). Is torture reliably assessed and a valid indicator of poor mental health? Journal of Nervous \& Mental Disease, 199, 3-10. doi:10.1097/NMD.0b013e3182051501

Hooberman, J., Rosenfeld, B., Lhewa, D., Rasmussen, A., \& Keller, A. (2007). Classifying the torture experiences of refugees living in the United States. Journal of Interpersonal Violence, 22, 1-16. doi:10.1177/0886260506294999

Isakson, B. L., \&. Jurkovic, G. (2013). Healing after torture: The role of moving on. Qualitative Health Research, 23, 749-761. doi:10.1177/1049732313482048

Johnson, H., \& Thompson, A. (2008). The development and maintenance of post-traumatic stress disorder (PTSD) in civilian adult survivors of war trauma and torture: A review. Clinical Psychology Review 2008, 28, 36-47. doi:10.1016/j.cpr.2007.01.017

Kazdin, A. E., \& Weisz, J. R. (1998). Identifying and developing empirically supported child and adolescent treatments. Journal of Counseling and Clinical Psychology, 66, 19-36. doi:10.1037/0022-006X.66.1.19

Kira, I. (2001). Taxonomy of trauma and trauma assessment. Traumatology, 2, 1-14.
Kira, I. (2002). Torture assessment and treatment: The wraparound approach. Traumatology, 8, 23-51.

Kira, I. (2010). Etiology and treatments of post-cumulative traumatic stress disorders in different cultures. Traumatology: An International Journal, 16, 128-141.

Kira, I., Templin, T., Lewandowski, L., Ashby, J. S., Oladele, A., \& Odenat, L. (2012a). Cumulative trauma disorder scale: Two studies. Psychology, 3, 643-656. doi:10.4236/psych.2012.39099

Kira, I., Ahmed, A., Wassim, F., McAdams-Mahmoud, V., Clorain, J., $\&$ Rai, D. (2012b). Group therapy for refugees and torture survivors: Treatment models innovations. International Journal of Group Psychotherapy, 62, 63-83. doi:10.1521/ijgp.2012.62.1.69

Kira, I., Fawzi, M., \& Fawzi, M. (2012). The dynamics of cumulative trauma and trauma types in adults patients with psychiatric disorders: Two cross-cultural studies. Traumatology, Advanced online Publication.

Kira, I., Templin, T., Lewandowski, L., Ramaswamy, V., Bulent, O., Abu-Mediane, S., Mohanesh, J., \& Alamia, H. (2011). Cumulative Tertiary appraisal of traumatic events across cultures: Two studies. Journal of Loss and Trauma: International Perspectives on Stress \& Coping, 16, 43-66. doi:10.1080/15325024.2010.519288

Kira, I., Ahmed, A., Mahmoud, V., \& Wassim, F. (2010). Group therapy model for refugee and torture survivors. Torture: An International Journal, 20, 108-113.

Kira, I., Smith, I., Lewandowski, L., \& Templin, T. (2010). The effects of perceived gender discrimination on refugee torture survivors: A cross-cultural traumatology perspective. Journal of the American Psychiatric Nurses Association, 16, 299-306. doi: $10.1177 / 1078390310384401$

Kira, I., Lewandowsi, L., Templin, T., Ramaswamy, V., Ozkan, B., \& Mohanesh, J. (2010). The effects of perceived discrimination and backlash on Iraqi refugees' physical and mental health. Journal of Muslim Mental Health, 5, 59-81. doi:10.1080/15564901003622110

Kira, I., Lewandowsk, L., Templin, T., Ramaswamy, V., Ozkan, B., \& Mohanesh, J. (2008). Measuring cumulative trauma dose, types and profiles using a development-based taxonomy of trauma. Traumatology, 14, 62-87. doi:10.1177/1534765608319324

Kira, I., Hammad, A., Lewandowski, L., Templin, T., Ramswamy, V., Ozkan, B., \& Mohanesh, J. (2007). The health and mental status of Iraqi refugees and their etiology. Ethnicity \& Disease, 17, 79-82.

Kira, I., Templin, T., Lewandowski, L., Clifford, D., Wiencek, E., Hammad, A., Al-Haidar, A., \& Mohanesh, J. (2006). The effects of torture: Two community studies. Peace and Conflict: Journal of Peace Psychology, 12, 205-228. doi:10.1207/s15327949pac1203 1

Kruse, J., Joksimovic, L., Cavka, M., Wöller, W., \& Schmitz, N. (2010). Effects of trauma-focused psychotherapy upon war refugees. Journal of Traumatic Stress, 22, 585-592.

McColl, H., Higson-Smith, C., Gjerding, S., Omar, M., Rahman, B., Hamed, M., et al. (2010). Rehabilitation of torture survivors in five countries: Common themes and challenges. International Journal of Mental Health Systems, 4, 16. doi:10.1186/1752-4458-4-16

Miller, K. E. (1999). Rethinking a familiar model: Psychotherapy and the mental health of refugees. Journal of Contemporary Psychotherapy, 29, 283-306. doi:10.1023/A:1022926721458

Mollica, R., McInnes, K., Poole, C., \& Tor, S. (1998). Dose effect relationship of trauma to symptoms of depression and PTSD among Cambodian survivors of mass violence. British Journal of Psychiatry, 173, 482-488. doi:10.1192/bjp.173.6.482

Neuner, F., Kurreck, S., Ruf, M., Odenwald, M., Elbert, T., \& Schauer, M. (2009). Can asylum seekers with posttraumatic stress disorder be successfully treated? A randomized controlled pilot study. Cognitive Behavior Therapy, 34, 1-11.

O'Brien, R. M. (2007). A caution regarding rules of thumb for variance inflation factors. Quality and Quantity, 41, 673-690. doi:10.1007/s11135-006-9018-6

Ortmann, J., Genefke, I., Jakobsen, L., \& Lunde, I. (1987). Rehabilitation of torture victims: An interdisciplinary treatment model. American Journal of Social Psychiatry, 7, 161-167.

Pope, K. S. (2001). Torture. In J. Worrell's (Ed.), Encyclopedia of women and gender: Sex similarities and differences and the impact of society on gender (pp. 1-1256). San Diego, CA: Academic Press. 


\section{A. KIRA ET AL}

Punamäki, R., Qouta, S. R., \& EI Sarraj, E. (2010). Nature of torture, PTSD, and somatic symptoms among political ex-prisoners. Journal of Traumatic Stress, 23, 532-536. doi:10.1002/jts.20541

Quiroga, J., \& Jaranson, J. (2005). Politically-motivated torture and its survivors: A desk study review of the literature. Torture, 15, 1-111.

Rasmussen, A., Rosenfeld, B., Reeves, K., \& Keller, A. S. (2007). The effects of torture-related injuries on long-term psychological distress in a Punjabi Sikh sample. Journal of Abnormal Psychology, 116, 734-740. doi:10.1037/0021-843X.116.4.734

Robjant, K., \& Fazel, M. (2010). The emerging evidence for narrative exposure therapy: A review. Clinical psychology review, 30, 10301039. doi:10.1016/j.cpr.2010.07.004

Schmitt, N. (1996). Uses and abuses of coefficient alpha. Psychological Assessment, 8, 350-353. doi:10.1037/1040-3590.8.4.350

Steel, Z., Chey, T., Silove, D., Marnane, C., Bryant, R. A., \& van Ommeren, M. (2009). Association of torture and other potentially trau- matic events with mental health outcomes among populations exposed to mass conflict and displacement: A systematic review and meta-analysis. Journal of the American Medical Association, 302, 537-549. doi:10.1001/jama.2009.1132

Summerfield, D. (2004). Cross-cultural perspectives on the medicalization of human suffering. In G. M. Rosen (Ed.), Posttraumatic stress disorder: Issues and controversies (pp. 233-245). New York: Wiley. doi:10.1002/9780470713570.ch12

Vorbrüggen, M., \& Baer, H. U. (2007). Humiliation: The lasting effect of torture. Military Medicine, 172, S29-S33.

Zerach, G., Greene, T., Ginzburg, K., \& Solomon, Z. (2013). The Relations between posttraumatic stress disorder and persistent dissociation among ex-prisoners of war: A longitudinal study. Psychological Trauma: Theory, Research, Practice, and Policy. Advance online publication. 